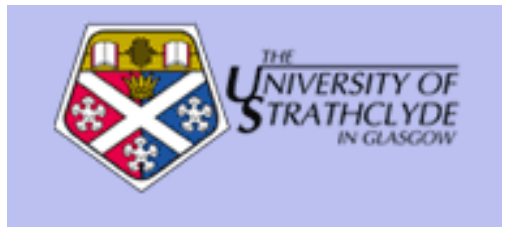

Palazzetti, Roberto and Trendafilova, I. and Zucchelli, Andrea and Minak, Giangiacomo (2010) Delamination localization and length estimation in composite laminate beam by VSHM and pattern recognition methods. Composite Structures . ISSN 0263-8223

http://strathprints.strath.ac.uk/25576/

This is an author produced version of a paper published in Composite Structures . ISSN 0263-8223. This version has been peer-reviewed but does not include the final publisher proof corrections, published layout or pagination.

Strathprints is designed to allow users to access the research output of the University of Strathclyde. Copyright (C) and Moral Rights for the papers on this site are retained by the individual authors and/or other copyright owners. You may not engage in further distribution of the material for any profitmaking activities or any commercial gain. You may freely distribute both the url (http://strathprints.strath.ac.uk) and the content of this paper for research or study, educational, or not-for-profit purposes without prior permission or charge. You may freely distribute the url (http://strathprints.strath.ac.uk) of the Strathprints website.

Any correspondence concerning this service should be sent to The Strathprints Administrator: eprints@cis.strath.ac.uk 


\title{
DELAMINATION LOCALIZATION AND LENGTH ESTIMATION IN COMPOSITE LAMINATE BEAM BY VSHM AND PATTERN RECOGNITION METHODS
}

\author{
Roberto Palazzetti ${ }^{*}$, Irina Trendafilova ${ }^{\dagger}$, Andrea Zucchelli ${ }^{*}$ and Giangiacomo Minak ${ }^{*}$ \\ Engineering Faculty, Mechanical Engineering Department \\ University of Bologna \\ Viale del Risorgimento 2, 40136 Bologna, Italy \\ e-mail: a.zucchelli@unibo.it \\ ${ }^{\dagger}$ Department of Mechanical Engineering \\ University of Strathclyde \\ James Weir Building, 75 Montrose Street, Glasgow, UK \\ e-mail: irina.trendafilova@strath.ac.uk
}

Key words: Vibration-based damage detection, Composite beam, Delamination detection, Numerical Analysis.

\section{SUMMARY.}

The focus of this work is to investigate the delamination damage in laminate composite beams, to fix a Vibration-based structural health monitoring (VSHM) method for the laminate structures. The analysis is concentrated on the vibration characteristics of the samples and, in particular, the attention is addressed on the first several natural frequencies of a composite laminate beam with a delamination damage. The core of this work is an experimental investigation on the vibration response of a composite laminate beam and its changes caused by delaminations with different sizes and in different locations of the beam. The study is divided in 3 sections: delamination detection, delamination localization, and delamination estimate. The aim is to determine how the first six harmonics frequencies change due to the delamination, and the results show that they can be successfully used to investigate the presence, the location and the dimensions of the delamination in a composite beam. A Pattern Recognition analysis is used to locate the damage, while the detection and the evaluation are done using the changes in the harmonic frequencies. A finite element analysis is performed, and the variations of the natural frequencies due to delamination are in good agreement with the experimental results.

\section{Introduction}

Composite materials form about $70 \%$ of contemporary civil and military aircraft. Aircraft safety is paramount because an accident will normally have catastrophic consequences in terms of casualties, destruction and the environment. Composites are hard to inspect for flaws 
and difficult, if not impossible, to repair. Composite materials can loose up to $60 \%$ of their stiffness and toughness, and still remain visibly unchanged. These are some of the reasons that make structural health monitoring for composite materials an issue of great importance. Delamination is one of most common failure mechanisms for composite materials. Delamination problem is as old as composite material. In laminated materials repeated cyclic stresses, impact, and so on can cause layers to separate, forming a mica-like structure of separate layers, with significant loss of mechanical strength. Thus, delamination is an insidious kind of failure as it develops inside of the material, without being obvious on the surface.

Delamination failure may be detected in the material by its sound [1,2]: solid composite has bright sound, while delaminated part sounds dull. Other nondestructive health monitoring (NDHM) methods include embedding optical fibers coupled with optical time domain reflectometer testing [3], testing with ultrasound [1,2], radiographic imagining [1,4], infrared imaging [1,5], in some cases acoustic emission monitoring [1,6,7], and vibration-based measuring methods $[2,8]$. Among NDHM methods the vibration-based methods is a suitable tool for damage detection which has been scarcely explored except for several papers devoted to vibration based monitoring for delamination detection [2].

Vibration-based structural health monitoring (VSHM) methods use the vibration response of a structure in order to find out its health. In VSHM methods the information from vibration parameters (modal frequencies, mode shapes and modal damping ratio) or combinations of some of them are used to estimate the variations of a structure mechanical response when damaged. The basic idea of these methods is that modal parameters are functions of the physical and mechanical properties of the structure (mass, damping and stiffness). In particular changes in the mechanical properties, such as the stiffness reduction, will cause changes in the modal characteristics. The measure of the vibration response of a structure before and after a damaging event enable the possibility to estimate the damage localization and entity. In the case of composite structure the usage of VSHM has been applied to investigate two main failure modes: the matrix crack and the delamination. A comprehensive literature review of this studies is presented in $[9,10]$. In particular it is interesting to cite the works of Lifshitz and Rotem [11] who measured resonant frequencies and damping on quartzparticle-filled epoxy and polyester. The authors found damping to be more sensitive to damage than changes in the dynamic moduli. Schultz and Warwick [12] measured the forced vibration response of glass-fiber-reinforced epoxy beams at various intervals during fatigue loading. They found changes in the resonant frequencies to be relatively insensitive to 
damage. They also found, however, that the damping ratio and response magnitude were very sensitive to damage. Adams, et al. [13] tested and glass-reinforced plates to attempt to detect damage after both static and fatigue torsional loading. The main mode of failure was matrix shear cracking. They found damping changes to be more sensitive than frequency shifts for detecting the onset of damage. They also noted that some changes in dynamic properties in the early stages of damage could be recovered after a rest period. Cawley and Adams [14] apply a frequency-shift-based damage detection routine to several damage cases (holes, saw cuts, crushing with a ball bearing, local heating with a flame, and impact) in composite materials (CFRP plates and honeycomb panels with CFRP faces). They were able to locate low levels of damage accurately. This successful location did require, however, controlled temperatures and testing of the undamaged and damaged specimens in a short amount of time to prevent long-term frequency shift. Reddy, et al. [15] experimentally measured natural frequencies in composite plates containing delaminations. Graphite fiber/epoxy resin panels with a $[ \pm 45,0,90]_{2 \mathrm{~s}}$ layup were used with delaminations comprising $10 \%$ of the total panel area. They found that the resonant frequencies were insensitive to the delaminations, even taking into account the higher modes. Lee, et al. [16] looked at the damping loss factor as a possible indicator for detecting and locating four types of damage in composites beam: notches that removed less than $5 \%$ of the cross-sectional area, matrix cracking in the 90 degree plies of a $\left[90_{2} / 0_{19} / 90_{2}\right]$ glass/epoxy composite, In all cases, cantilever beams were excited with a force hammer. They found that the change in the damping loss factor was always more sensitive to damage than the frequency change was. Tracy and Pardoen [17] experimentally examined frequency shifts in graphite-epoxy laminates with midplane delaminations. The resulting frequency shifts corresponded well with the analytical predictions. Engblom and Havelka [18] quantified, both numerically and experimentally, the effects of fibre breakage, matrix cracking, local buckling, and delamination based on variations in stiffness and damping characteristics. Sanders, et al. [19] measured modal parameters on damaged graphite/epoxy $\left[0 / 90_{3}\right]_{\mathrm{s}}$ beams. Damage was induced by tensile loading the beams to $60 \%, 75 \%$, and $85 \%$ of the ultimate tensile strength. Damage was predicted using a sensitivity method and the measured frequencies. Because the measured mode shapes were of poor resolution, they were not used in the prediction. Results agreed well with independently obtained results based on static stiffness measurements and crack densities from edge replication. Because this damage was approximately uniform throughout the beam, the ability of the method to localize damage was not demonstrated. Nokes and Cloud [20] used laser Doppler vibrometry and electronic speckle pattern interferometry to 
measure modal parameters on a composite beam at high frequencies (up to $10 \mathrm{kHz}$ ) with high spatial resolution. They found the damping loss factor to be a sensitive indicator of global material damage. Diaz Valdes and Soutis [21] used a novel method known as resonant ultrasound spectroscopy to determine the modal frequencies of a composite beam obtained from an eight-ply [0/90/90/0 $]_{\mathrm{s}}$ carbon/epoxy laminate of size $330 \mathrm{~mm}$ x $300 \mathrm{~mm}$. The laminate was fabricated using T800-924C prepreg tapes. They used commercial, brass backed, piezoceramic transducer and a piezoelectric film element (AMP Inc., LDTO-028-K) bonded near the beam's fixed end and operated as actuator and sensor respectively. Changes of the modal frequencies after delamination initiation, compared to those of a nondelaminated specimen, gave a good indication of the degree of damage, demonstrating the feasibility of using measured changes in the vibration characteristics to detect damage.

In this work, the VSHM is used to develop a simple delamination detection which is based only on changes in the harmonic frequencies of a structure. The proposed method utilizes the first several natural frequencies of a structure which are a rather easy and straightforward to be precisely estimated from experiment. The study is based mainly on experimental results and numerical analysis are performed on delaminated beam only for the purpose to support the delamination localization. From the study it emerged that by a damage index based on the first natural frequency it is possible to discriminate the presence or absence of a critical delamination, and also that it was possible to determine, with a $95 \%$ of confidence, where the delamination is located. Moreover by the relation between the variation of first natural frequency (damage index) and the delamination length it is possible to determine the size of damage.

The paper is organised as follows. In paragraph 2 the tested beams and the way used to introduce the delamination are presented. It also discusses the different sizes and positions of the delamination as well as the measurement points positions. The experiment performed and the numerical model are described here as well. Paragraph 3 presents the results for the natural frequencies of the healthy beam and the ones obtained for different delamination sizes and locations as well as for different positions of the delamination. It was done to track and find trends in the changes that the natural frequencies experience with delamination. A damage index based on the first natural frequencies is suggested. The last paragraph discusses the obtained results and makes conclusions regarding the application of the first several natural frequencies for damage detection, localization and quantification of delamination in composite beams. 


\section{Materials and Methods}

The structures considered are composite beams made by prepreg of carbon fibers (T300) embedded in a epoxy resin (SE 84 SP-Gurit) with a $60 \%$ of fibers volume ratio and a density of $300 \mathrm{~g} / \mathrm{m}^{2}$. Laminate lay-up was cross ply [0/90]10s. The beams were manufactured with a length of $350 \mathrm{~mm}$, a width of $30 \mathrm{~mm}$ and $1.7 \mathrm{~mm}$ thick. The thickness is made of ten layers. It is used this kind of structure because its shape is appropriate for the purposes: it is thin, therefore it is possible to have wide amplitude with a small force. This fixing condition was adopted because it mimics better a real structural part than a free-free beam and also because the tests are quite easy to do. Delamination was introduced artificially by inserting a Teflon sheet in the desired position. The artificial introduction has the advantage that the delamination can be introduced exactly with the desired size and in the desired position but it has the disadvantage that different specimens are tested: for these reasons special care was taken that all the specimens are identical in terms of dimensions. Two different sizes of delamination were introduced: "long" and "short". The small one is $115 \mathrm{~mm}$ long and the big one is $175 \mathrm{~mm}$ long. Three different positions of the delamination along the beam length were tested, namely back (starting at the clamped end), middle and front. The positions of the delamination are shown in Figure 1.

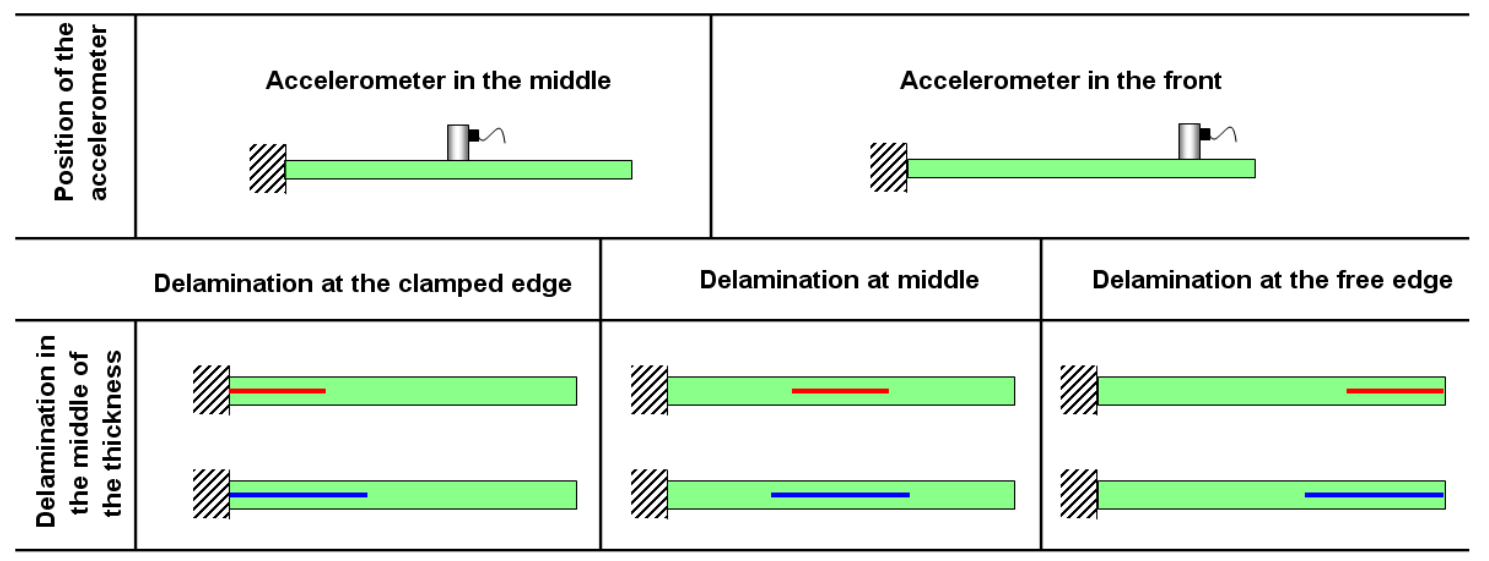

Figure 1 - scheme of the position of the accelerometer and of the delamination

Beams were excited with a "Bump Test", which was done by clamping the beam at one end and stimulating the structure at the free end, while an accelerometer, fixed above the beam registers the response. This kind of test is safer than others which use sine solicitation, and it is easier; moreover, for the purpose of this work the magnitude of the vibration is not considered, but only in the harmonic frequencies are studied. Typical excitation signals for 
this kind of tests are impulse, broadband, swept sine, and chirp. Each has its own advantages and disadvantages. In this work it is been used an impulse signal exerted by a hammer, hitting the free end of the samples. The quantity to be measured is the motion during the vibration, so it is necessary to use an accelerometer: a piezoelectric one was used. To constrain beams it was decided to use a $\mathrm{G}$ - clamp on a stiff table. In order not to damage the item in the contact point with the clamp, a slab made of stiff rubber was interposed between the elements in contact (clamp-beam and table-beam). Beams were clamped in the way to leave a free length of $300 \mathrm{~mm}$ for all the experiments. Two different positions of the accelerometer were explored as well: it was placed in the middle of the beam, 150 from the clamping and close to the free end, $225 \mathrm{~mm}$ from the clamped end. The reason for this choices is that the different vibration modes have different node points where the displacement is null or very close to zero. The middle position is expected to be close to a node point for some modes e.g. the third and the fifth modes, but it is a point of large amplitude displacements for other modes e.g. the first, the second and the fourth mode. Thus it would be appropriate for analyzing some modes. The end position is not expected to be a node point for any of the lower modes for a cantilever beam. Six different configurations of delaminated beams were manufactured, each one of them tested twice, changing the position of accelerometer. Because of the possible errors in the manufacturing process, it was decided to manufacture 3 identical items for each configuration, and repeat each tests 5 times for every configuration obtaining in this way the harmonic frequencies from the average of the results for each signal: thus 30 data sets were obtained for each specimen, for every position of the transducer. It was the same for the nondelaminated beams: the test was repeated on 3 identical items, 5 times for each position. In this way 3 specimens for each one of the 7 different configurations (1 undamaged and 6 damaged) were obtained, and tests for each specimen were repeated 5 times for both position of the accelerometer.

Numerical analysis have to simulate the test condition, thus the most important and critical aspect is simulate the impulse. It is impossible with a modal analysis, so a Transient Analysis was used. The impulse for transient analysis was simulated by a squared function, shown in figure 2, that was applied to the free end of the beam. 


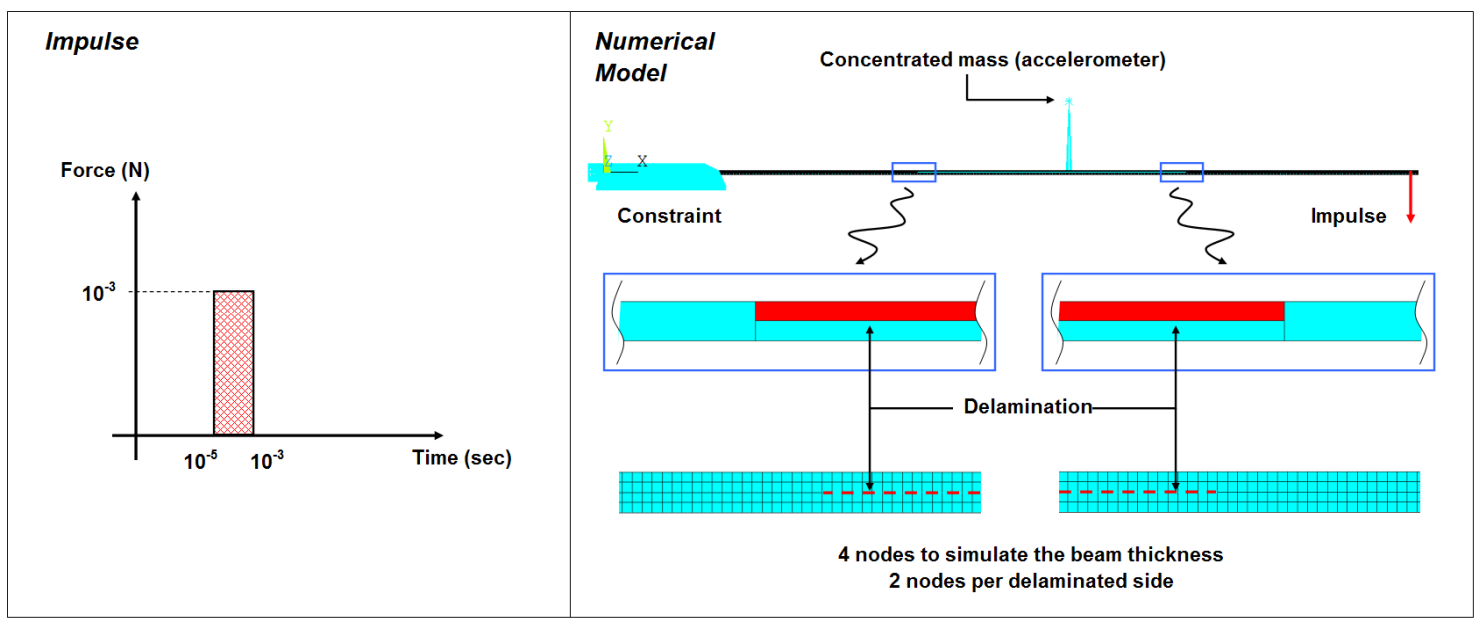

Figure 2 - Impulse characteristics and Numerical model details

The elements used are PLANE182 to model the beam, MASS21 to simulate the mass of accelerometer, LINK1 to connect the concentrated mass of the accelerometer to the beam, TARGE169 and CONTA172 to introduce the Contact Condition in the delaminated zone. Delamination was inserted into the geometry as a discontinuity, modelling the beam with more areas as shown in figure 2. For the purpose of numerical simulation the following material characteristic have been used: $\mathrm{E}_{\mathrm{x}}=\mathrm{E}_{\mathrm{y}}=44000 \mathrm{MPa}, \mathrm{v}=0.28$, density $=1600 \mathrm{~kg} / \mathrm{m}^{3}$. This analysis allows to determine the vibration of the beam with the purposes of confirm the experimental results and support the delamination localization procedure (\$3.2).

\section{Delamination detection and localization}

In this section the detection of the delamination, its localization and its length estimation using the natural frequencies is considered. In $\$ 3.1$ it is discussed the way to determine the occurrence of a delamination in the composite beam. In $\$ 3.2$ a simple method for the delamination localization based on the pattern recognition method is developed and applied to the delaminated beams. In $\S 3.3$ a methodology for the estimation of the delamination length based on the variation of the first natural frequency is shown.

3.1 Delamination detection. The main idea of this paragraph is to suggest a method to detect the presence of the delamination damage in the composite beam. This is done using the natural frequencies of the beam. As it is known that delamination results mainly in bending 
stiffness reduction then it can be expected to reduce the flexural natural frequencies of the structure [22] and especially the first natural frequency. In order to account this variation a damage index based on the variation of the first natural frequency is proposed. This index represents the experimentally obtained relative changes in per cent in the first natural frequency of the beam with the length of the delamination for different positions of the delamination. A further Finite Element analysis, which results in terms of variation of the first natural frequency are also summarized in figure 3 , confirmed the experimental ones.

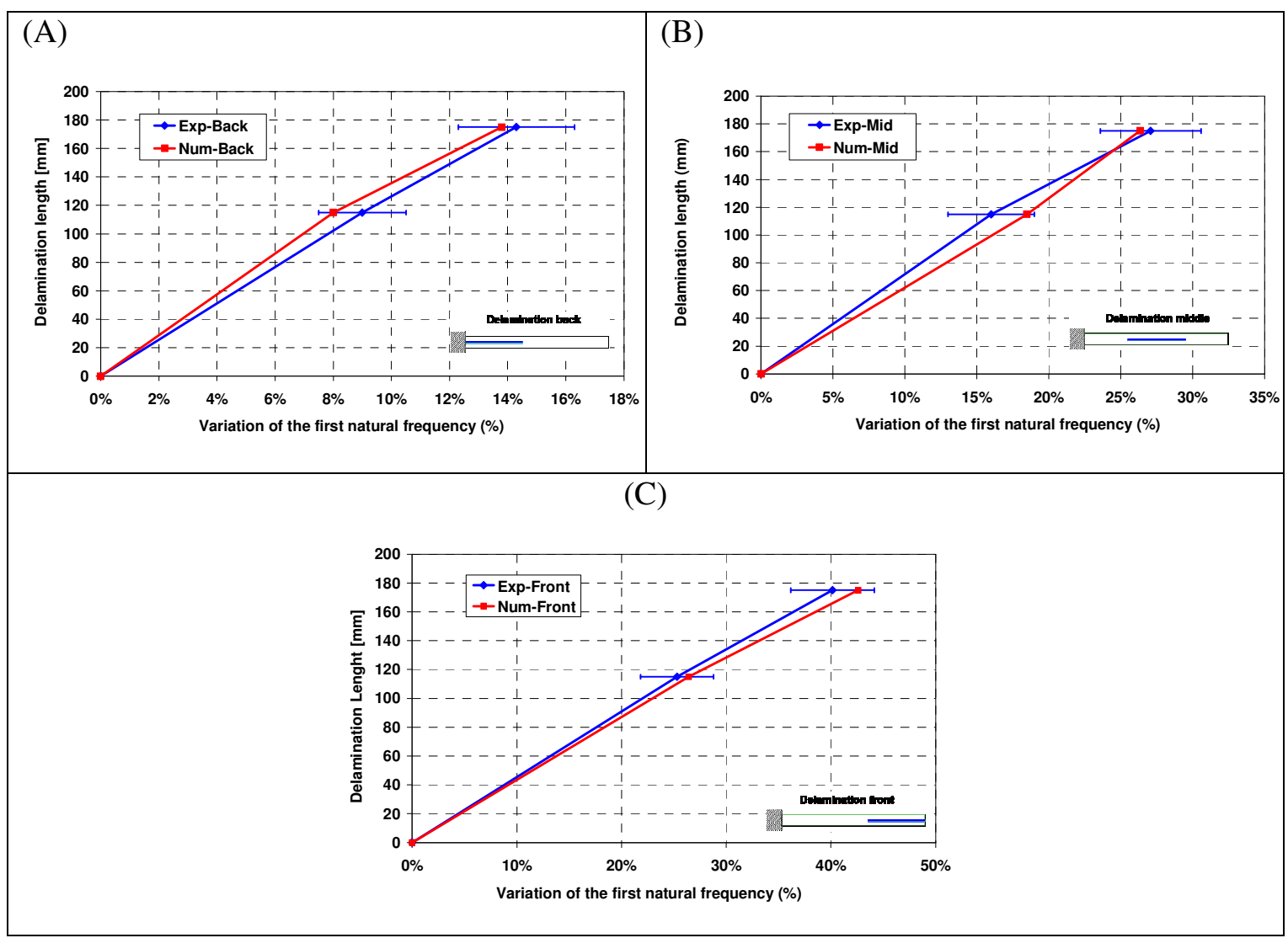

Figure 3 - Per-cent variation of the first natural frequency estimated for specimens having the delamination respectively in the clamped edge (A), in the middle (B) and in the free edge (C). Results in all diagrams are obtained by both experimental tests and numerical analysis

Another observation that can be done is that the changes are big enough even for the case of the smaller delamination length. Thus the following damage index can be suggested:

$$
\xi=\frac{f_{1}^{\text {undamaged }}-f_{1}^{\text {damaged }}}{f_{1}^{\text {undamaged }}}
$$

The above index is supposed to change between 0 and 1 . And thus the following detection rule can be suggested: 


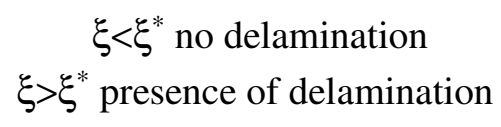

In the above rule $\xi^{*}$ is a threshold value and below that one can assume that there is no delamination while above this value it can be assumed that delamination is present in the beam. Normally this threshold value can be set to about 0.05 or $5 \%$. Changes below this value can be caused by a number of reasons including noise, temperature and environmental changes. Once the changes become bigger than the presence of delamination is quite likely so this might be set as an "alert" level in the detection. It was been created a testing sample of 900 signals (half of these were with no delamination and the other 500 corresponded to different levels and different positions of delamination) by adding noise between $3 \%$ and $5 \%$ (Gaussian noise) to the experimentally obtained vibration signals. From these results it was determined the first natural frequency and used it in the delamination index suggested above by equation (1). The alarm level was set to $10 \%$. The delamination index correctly detected the presence of delamination in $96 \%$ of the cases.

\subsection{Delamination localization.}

The question answered in this paragraph is whether localization of the position of the delamination with respect to the beam length is possible. The experimental results for the first several natural frequencies and the theoretically obtained ones were reviewed and it turned out a rather complicated task to find the boundaries for the different frequencies for the different delamination locations namely back (close to clamping), middle (around the midpoint of the beam) and front (close to the front of the beam, away from clamping). This is why the problem for damage detection and localization was formulated as a pattern recognition (PR) one [23-26]. Three different categories (classes) according to the possible location of the delamination are defined: delamination back (B), delamination middle (M) and delamination front $(\mathrm{F})$. This formulation suggests that one already suspect the presence of delamination in the structure. A PR problem suggests the recognition of the signals measured for the three different delamination locations on the basis of some features that can be extracted from these signals. Since it is clear that the natural frequencies are sensitive to damage and consequently to delamination six of the natural frequencies as features were chosen. These were chosen on the basis of the numerically obtained natural frequencies from the FE model of a clamped undamaged carbon fiber beam. The natural frequencies used are given in Table 1. It was also observed that the spectra of the measured responses for the undamaged as well as for the delaminated beams exhibit peaks close to these six frequencies with a certain variance which is also given in Table 1. These particular frequencies were chosen because they are not double ones and there are no other natural frequencies within the interval $\mathbf{f} \pm 2 \sigma$. Table 1 - The six natural frequencies used as features and the corresponding standard deviations.

\begin{tabular}{|c|c|c|c|c|c|}
\hline $\mathbf{f}_{1}$ & $\mathbf{f}_{2}$ & $\mathbf{f}_{3}$ & $\mathbf{f}_{4}$ & $\mathbf{f}_{5}$ & $\mathbf{f}_{6}$ \\
$\left(2^{\text {nd }}\right.$ natural & $\left(3^{\text {rd }}\right.$ natural & $\left(5^{\text {th }}\right.$ natural & $\left(7^{\text {th }}\right.$ natural & $\left(\mathbf{1 0}^{\text {th }}\right.$ natural & $\left(\mathbf{1 3}^{\text {th }}\right.$ natural \\
frequency & frequency $)$ & frequency $)$ & frequency $)$ & frequency $)$ & frequency $)$ \\
\hline
\end{tabular}




\begin{tabular}{|c|c|c|c|c|c|}
\hline$\mu=2.5 \mathrm{~Hz}$ & $\mu=4.9 \mathrm{~Hz}$ & $\mu=7.2 \mathrm{~Hz}$ & $\mu=52 \mathrm{~Hz}$ & $\mu=74 \mathrm{~Hz}$ & $\mu=112 \mathrm{~Hz}$ \\
$\sigma=20 \%$ & $\sigma=15 \%$ & $\sigma=7 \%$ & $\sigma=1 \%$ & $\sigma=1 \%$ & $\sigma=0.9 \%$ \\
\hline
\end{tabular}

In order to solve a PR problem it is been created a training sample of 1200 signals (400 for each category) measured for 1 second and sampled at $500 \mathrm{~Hz}$ (according to our model this is the expected range for the first six natural frequencies of the beam). This sample was created using 100 measured signals and adding Gaussian noise between 3\% and 5\% to the measured acceleration response signals. The next step was to test whether it is possible to recognize signals from the three defined categories using the first 6 natural frequencies. For the purpose a new testing of another 1200 signals was created, obtained using another 100 measured signals and adding Gaussian noise between 3\% and 5\%. The recognition was done using the $1-\mathrm{NN}$ method. According to the method each new signal is assigned to the category of its nearest neighbour. The Euclidean distance between vectors made of the first 6 natural frequencies of the beam was used a measure.

$d\left(\mathbf{f}^{1}, \mathbf{f}^{2}\right)=\sqrt{\sum_{i=1}^{6}\left(f_{i}^{1}-f_{i}^{2}\right)^{2}}$

Thus for each new vector of the testing sample the distances to all the vectors from the training sample were obtained and a vector $\mathbf{f}$ was categorized to the class $j$ if its nearest negihbour $\mathbf{f}^{j}$ belonged to that class:

$d\left(\mathbf{f}, \mathbf{f}^{j}\right)=\min _{k=1}^{1200} d\left(\mathbf{f}, \mathbf{f}^{k}\right)$

where $\mathbf{f}^{k}$ are the vectors from the training sample. The results from the testing are presented in terms of "confusion matrix" which contains the percentage of all the correctly classified and the miss-classified vectors $\mathbf{f}$ from the testing sample. The confusion matrix is given in Table 2. It can be seen that for the B and $M$ categories about $95 \%$ of the signals were correctly classified and only for the category $\mathrm{F}$ (front delamination) $89 \%$ were correctly recognized while the rest $11 \%$ were miss-classified.

Table 2 - Confusion matrix for the testing sample

\begin{tabular}{lccc}
\hline True category & Category B & Category M & Category F \\
\hline Category B & 95 & 3.5 & 1.5 \\
\hline Category M & 3 & 94 & 3 \\
\hline Category F & 4 & 7 & 89 \\
\hline
\end{tabular}


3.3 Delamination Length. The main idea of this paragraph is to suggest a method to determine the dimensions of the delamination located with the previous PR. This will be done using the damage index already mentioned above. It was been written the Damage Index for the different configurations of damaged beams, and the results are shown in Figure 4.

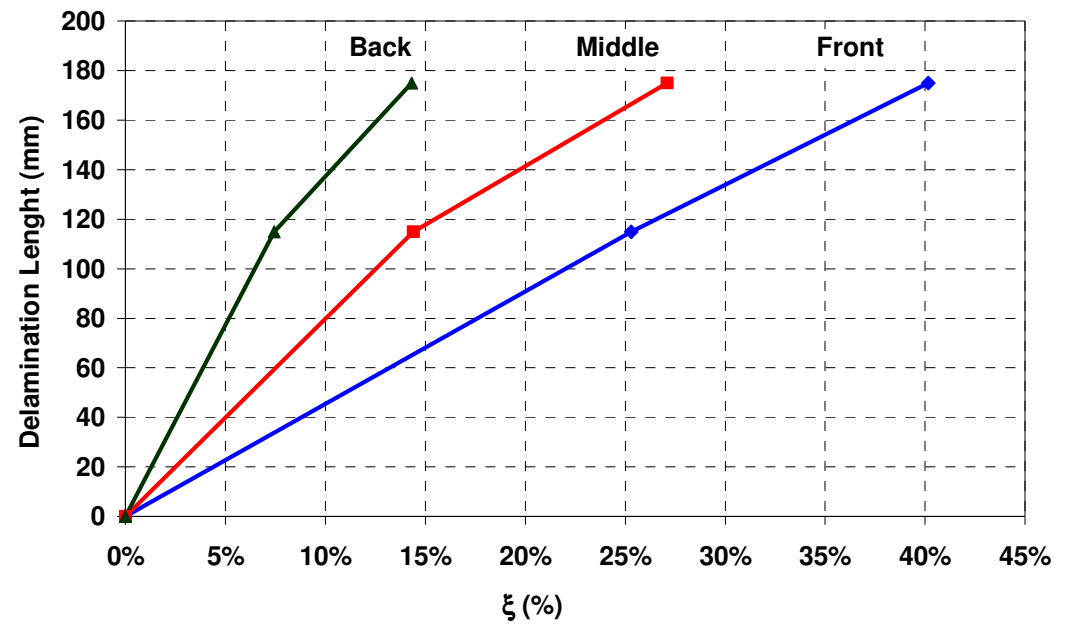

\section{Figure 4. Delamination index for different positions of delamination along the beam length}

When the delamination presence is confirmed as proposed in $\$ 3.1$, and located as described by the methodology exposed in $\S 3.2$, the knowledge of damage index $\xi$ enable the estimation of the delamination length.

\section{Conclusions.}

This investigation considered the problem for delamination detection, localization and quantification in a composite beam. It shown that it is possible to detect delamination in an easy and straightforward way with a rather high confidence: in more than $90 \%$ of the cases the presence of delamination is detectable and it is possible to locate and quantify it. The starting point was to hypothesize that the structure can be affected only by delamination, and the first step was to detect it. This first step was done using the vibration response of the structure, and comparing it with one another, done before the working period, in the same condition. The focus was on the first natural frequency for the both signals, and it was been possible to establish if the delamination was present on the structure. If the delamination was detected, the second step is to locate it, and it was possible with a Pattern Recognition method, which used the first several natural frequencies of the signal obtained with the vibration analysis. The investigation shown that the localization was possible with a rather high confidence which is about $95 \%$. This again permits the development of an automatic process which will deliver an answer about the location of delamination along the beam length with a rather high precision. The last step was to give information about the length of the delamination. It was possible automatically by using the proposed graphs and comparing it to a threshold value. Concluding, it is shown that it is possible, with one single experimenta vibration test- and using only the response vibration signal, to answer all the three questions 
mentioned above. It is a very good achievement, because in most damage assessment methods another experiment (e.g. acoustic emission) is needed to locate and/or quantify the fault.

\section{References}

[1] Peter J. Shull, Nondestructive Evaluation Theory, Techniques, and Applications, Marcel Dekker, Inc., 2002.

[2] S.W. Doebling, C.R. Farrar and M.B. Prime, A Summary Review of Vibration-Based Damage Identification Methods, The Shock and Vibration Digest, Vol. 30, No. 2, pp. 91-105, 1998

[3] R. Crane, A. Macander and J. Gagoric, Fibre optics for a damage detection system for fibre reinforced plastic composite structures, Rev Progr Quant Non-Destruct Eval 2B, pp. 1419-1430, 1982.

[4] Robert Crane, Donald Hagemaier, Robert Fassbender, Radiographic Inspection of Composites, Comprehensive Composite Materials, Chapter 5.13, Pages 321-344, 2003

[5] H.I. Ringermacher, B. Knight, J. Li, Y.A. Plotnikov, G. Aksel and D.R. Howard et al., Quantitative evaluation of discrete failure events in composites using infrared imaging and acoustic emission, Nondestruct Test Eval 22 (2-3), pp. 93-99, 2007

[6] G. Minak, A. Zucchelli, Damage Evaluation and Residual Strength Prediction of CFRP Laminates by means of Acoustic Emission Techniques, a cura di LUCAS P. DURAND. Composite Materials Research Progress. (pp.1-45). ISBN: 1-60021-994-2. HAUPPAUGE NY: Nova Science Publishers, Inc.

[7] Igor M. De Rosa, Carlo Santulli, Fabrizio Sarasini, Acoustic emission for monitoring the mechanical behaviour of natural fibre composites: a literature review, Composites Part A: Applied Science and Manufacturing, In Press, Accepted Manuscript, Available online 10 May 2009

[8] Clarence W. de Silva, Vibration Monitoring, Testing, and Instrumentation, CRC Press Taylor \& Francis Group

[9] Scott W. Doebling, Charles R. Farrar, Michael B. Prime, Daniel W. Shevitz, Damage Identification and Health Monitoring of Structural and Mechanical Systems from Changes in Their Vibration Characteristics: A Literature Review, Los Alamos National Laboratory, 1996 
[10] Y. Zou, L. Tong, G. P. Steven, Vibration-Based Model-Dependent Damage (Delamination) Identification and Health Monitoring for Composite Structures - A Review, Journal of Sound and Vibration, 230(2), 357-378, 2000

[11] Lifshitz, J.M., Rotem, A. Determination of Reinforcement Unbonding of Composites by a Vibration Technique, Journal of Composite Materials, 3 (3), p.412-423, Jan 1969

[12] Schultz, A. B., Warwick, D. N., Vibration Response: A Non-Destructive Test for Fatigue Crack Damage in Filament-Reinforced Composites, Journal of Composite Materials, 5 (3), p.394-404, Jan 1971

[13] Adams, R.D., D. Walton, J.E. Flitcroft, and D. Short, Vibration Testing as a Nondestructive Test Tool for Composite Materials, Composite Reliability, ASTM STP $580,159-175,1975$

[14] Cawley, P. and R.D. Adams, The Locations of Defects in Structures from Measurements of Natural Frequencies, Journal of Strain Analysis, 14 (2), 49-57, 1979.

[15] Reddy, A.D., L.W. Rehfield, and R.S. Haag, Influence of Prescribed Delaminations on Stiffness-Controlled Behavior of Composite Laminates, Effects of Defects in Composite Materials, ASTM STP 836, 71-83, 1984.

[16] Lee, B.T., C.T. Sun, and D. Liu, An Assessment of Damping Measurement in the Evaluation of Integrity of Composite Beams, Journal of Reinforced Plastics and Composites, 6, 114-125, 1987.

[17] Tracy, J.J. and G.C. Pardoen, Effect of Delamination on the Natural Frequencies of Composite Laminates, Journal of Composite Materials, 23, 1200-1215, 1989.

[18] Engblom, J.J. and J.J. Havelka, Combined Analytical/Experimental Approach for Developing Structural Model of Damaged Composite Structures, in Proc. of 32th AIAA/ASME/ASCE/AHS/ASC Structures, Structural Dynamics and Materials Conf., 1332-1340, AIAA-91-1085-CP, 1991.

[19] Sanders, D., Y.I. Kim and R.N. Stubbs, Nondestructive Evaluation of Damage in Composite Structures Using Modal Parameters, Experimental Mechanics, 32, 240-251, 1992.

[20] Nokes, J.P. and G.L. Cloud, 1993, The Application of Interferometric Techniques to the Nondestructive Inspection of Fiber-reinforced Materials, Experimental Mechanics, 33, 314-319.

[21] S. H. Diaz Valdes, C. Soutis, Delamination Detection in Composite Laminates from Variations of their Modal Characteristics, Journal of Sound and Vibration, 228(1), 1-9, 1999. 
[22] Christian N. Della, Dongwei Shu, Vibration of Delaminated Composite Laminates: A Review, Applied Mechanics Reviews, January 2007, Vol. 60, 1-20

[23] I. Trendafilova, W. Heylen, Categorization and Pattern Recognition methods for Damage Localization from Vibration Measurements, 2003, Mechanical Systems and Signal Processing, 17 (4), pp 825-836.

[24] I. Trendafilova, A study on vibration-based damage detection and location in an aircraft wing scaled model, Applied Mechanics and Materials, vol 3-4 (2005), pp 309-314

[25] J.T. Tou, R. C. Gonzales, Pattern recognition principles Addison-Wesley Publ. Comp (1974)

[26] H. Sohn, Charles R. Farrar, Norman F. Hunter, and Keith Worden, Structural Health Monitoring Using Statistical Pattern Recognition Techniques, ASME Journal of Dynamic Systems, Measurement 